\title{
An update on contraindications for lung function testing
}

\author{
Brendan G Cooper
}

\section{Correspondence to}

Brendan G Cooper, Lung Investigation Unit, University Hospitals Birmingham NHS Foundation Trust, Edgbaston, Birmingham B10 2TH, UK; brendan.cooper@uhb.nhs.uk

Received 31 March 2010 Accepted 11 May 2010

Published Online First

29 July 2010

\begin{abstract}
Guidelines on contraindications for lung function tests have been based on expert opinion from $>30$ years ago. High-risk contraindications to lung function testing are associated with cardiovascular complications such as myocardial infarct, pulmonary embolism or ascending aortic aneurysm. Slightly less risky but still serious contraindications are predominantly centred on recovery from major thoracic, abdominal or head surgery. Less serious surgical procedures will present a possible risk, but the RR depends upon whether the lung function is essential or can wait until the patient's condition improves. In recent decades there have been moves towards less invasive surgical techniques, keyhole surgery and new technology such as laser surgery which minimise the amount of collateral damage to surrounding tissues. In thoracic surgery there is a shift in emphasis to quicker postsurgical mobility. Furthermore there has been little analysis of the scientific facts behind the current recommendations and contraindications. The principle absolute and relative contraindications are in need of revision, and recommended times of abstaining from lung function tests needs to be reviewed. This review aims to outline the key issues and suggests newer recommendations for contraindications for performing lung function using a risk matrix, as well as offering alternative approaches to testing patients who may be at risk of complication from testing. In general, the previous recommendation of waiting for 6 weeks after surgical procedures or medical complications before performing lung function can often now be reduced to $<3$ weeks with modern less invasive surgical techniques.
\end{abstract}

\section{INTRODUCTION}

As lung function testing, and particularly spirometry, becomes more widespread across primary and secondary, care there are greater numbers of practitioners and commissioners who are unaware of the potential harm and discomfort that these tests can cause to some patients. International guidelines on contraindications for lung function tests ${ }^{1}$ have been cited by many sources ${ }^{3}$ but their evidence base is generally from the USA and is founded only on expert opinion which is now $>30$ years old. ${ }^{4-7}$ Recent developments in surgical practice and technology have decreased the invasive nature of procedures, so some of the contraindications may now need modification.

This paper aims to review the evidence base for these contraindications and, where it is lacking, examine the known facts around the potential problems in order to suggest new recommendations. In the current culture of evidence-based medicine, this is a timely and worthwhile review that needs wide dissemination and discussion in order to formulate new guidelines.

Contraindications generally fall under the umbrella of risk management and clinical governance issues in most health centres. Risk management is made up of two components (1) the likelihood of the event happening and (2) the severity of the consequences for the patient if it happens. In most areas of respiratory physiology testing, the likelihood of an adverse event is very low and many often have relatively minor (nonlife-threatening) consequences (eg, cataract detachment during spirometry). Even the more serious surgical complications such as rupture of an aortic aneurysm which has an absolute prevalence of only $7.1 \%$ in men and $1.6 \%$ in women ${ }^{8}$ are relatively rare, so the likelihood of these happening during spirometry is very rare. Postponed lung function testing due to current contraindications in our experience is only $\sim 0.3-0.5 \%$ (personal communication, ARTP website Forum 2009). A suggested table of relative risks appears in appendix 1 .

Contraindications can be considered as being 'relative' or 'absolute'. Most contraindications are relative and require the requesting physician/ healthcare expert to judge when it is safe and appropriate to undertake the breathing test. Absolute contraindications are those that would cause trauma, injury or death to the patient if they were undertaken. Sometimes the contraindication just means that the test is unnecessary or unlikely to be of real clinical benefit to a compromised patient, and a lung function test would be better when they are remote from surgery or infection. Similarly, a dogmatic approach of refusal to test patients with any contraindication needs to be tempered.

The main principle of performing lung function tests is that the risks of the procedure will provide information that will be outweighed by the benefit the patient's assessment for operation or treatment provides. If the reverse is true and the lung function test does not entail any benefit for the level of risk sustained, then the test should not be undertaken. Close liaison between surgical staff, medical staff and healthcare scientists/technologists in lung function should eradicate most unnecessary risk to patients.

The key relative contraindications cited by the 1996 American Association for Respiratory Care (AARC) documents ${ }^{1}$ are:

- Haemoptysis of unknown origin (forced expiratory manoeuvre may aggravate the underlying condition);

- Pneumothorax; 
- Unstable cardiovascular status (forced expiratory manoeuvre may worsen angina or cause changes in blood pressure) or 'recent' myocardial infarction or pulmonary embolus;

- Thoracic, abdominal or cerebral aneurysms (danger of rupture due to increased thoracic pressure);

- 'Recent' eye surgery (eg, cataract);

- Presence of an acute illness or symptom that might interfere with test performance (eg, nausea, vomiting); and

- Recent thoracic or abdominal surgery.

These recommendations are based on very little concrete evidence. $^{4-7}$ and to date there have been no randomised controlled trials (RCTs) published in this area. Each of these key issues will be reviewed in this paper and, where possible, new recommendations will be suggested.

\section{POTENTIAL HARM FROM LUNG FUNCTION TESTS}

The most likely harm from lung function testing originates probably from four key factors:

1. Maximal pressures generated in the thorax and their impact on abdominal and thoracic organs/tissues.

2. Large swings in blood pressure causing stresses on tissues in the body (head, limbs, etc.).

3. Expansion of the chest wall and lungs.

4. Active communicable diseases (tuberculosis (TB), hepatitis B, HIV, etc.).

It is worth noting that postoperative physiotherapy including encouraging deep breathing, coughing and incentive spirometry after thoracic surgery is actually thought to be beneficial in terms of reversing atelectasis, thus reducing the risk of pneumonia. ${ }^{8} 9$ Similarly in cardiothoracic surgery the emphasis is now shifting towards earlier mobilisation of the patient postoperatively in order to re-establish normal respiration rather than a policy of avoiding activity. 910

Many contraindications have a higher risk, with the more volitional tests involving forced manoeuvres such as spirometry, maximum mouth pressures and possibly full exercise tests. However, considerable information can be gained from less forced tests such as oscillometry, relaxed vital capacity, static lung volume assessment, gas transfer and some of the field tests (incremental shuttle walking test (ISWT), 6 minute walking distance (6 MWD)) and of course blood gas analysis and oximetry. Use of lower risk/less strenuous tests should always be considered by the referring physician/surgeon or the staff running lung function services.

\section{RECENT SURGERY}

\section{Tissue healing time}

It is well documented that the healing process requires platelets and macrophages that are essential to wound healing. Platelets participate in the initiation of the healing process by releasing local growth factors that stimulate connective tissue repair and macrophage activity. After the first $24 \mathrm{~h}$, the macrophages produce the growth factors needed to continue the healing process. The three steps of healing: (1) inflammation/reactive, (2) proliferation/reparative and (3) remodelling/maturational are all orchestrated by circulating and local factors that drive the wound healing. ${ }^{11-13}$

General healing times are reported in many textbooks and practice guidelines, but these can only be a guide since there is understandably a large variation depending upon individual circumstances. Table 1 shows some typical values from occupational health organisations as a guide to healing time. At least $5 \%$ of patients undergoing a surgical procedure develop a surgical site infection. The National Institute for Health and Clinical
Excellennce (NICE) has published general recommendations on surgical site infection and healing (http://www.nice.org.uk/ nicemedia/pdf/CG74NICEGuideline.pdf).

'Healing time' is a general term and may refer to functional healing rather than tissue repair, and does not of course mean that patients could not perform lung function tests before this time. The time taken before maximal manouevres would cause damage to the surgical area (eg, rupture stitches, etc.) or pain to the patient needs to be considered. Also, there are a number of risk factors which prolong healing, including smoking, diabetes, age, poor nutritional status and general health. ${ }^{11-13}$

Surgical procedures that could be affected by lung function testing include the following categories:

- Abdominal surgery.

- Eye surgery.

- Thoracic surgery.

- Ear surgery.

- Brain surgery.

\section{ABDOMINAL SURGERY}

Generally, the more muscular damage involved in abdominal surgery, the longer the time for healing is required.

\section{Laparotomy}

Laparotomy for abdominal surgery is increasingly being reduced by using laparoscopy involving 'keyhole' techniques. A recent Cochrane review ${ }^{14}$ has shown that people who have keyhole procedures can return to their normal daily activities on average 3-4 days earlier than those who have open surgery. One study on gastric bypass surgery comparing laparoscopic with conventional surgery ${ }^{15}$ has shown that lung function (forced expiratory volume in $1 \mathrm{~s}\left(\mathrm{FEV}_{1}\right)$ ) falls to $40 \%$ of the preoperative value on the first postoperative day, $50 \%$ by day 3 and $80 \%$ by day 7 . By day 7 there was no difference in lung function after either surgical technique. This suggests that meaningful spirometry can be performed if required within 1 week of abdominal surgery by either technique.

\section{Caesarean section}

The general consensus for the healing of an uncomplicated caesarean section is $\sim 6-8$ weeks. There is little evidence base for this except expert opinion.

\section{EYE SURGERY}

One of the potential risks from spirometry after eye surgery is the increase in intraocular pressure (IOP) producing damage to the wound site in the eye or damage to optic nerves or blood vessels. However, the size of this risk needs to be evaluated.

There is a logical relationship between increasing blood pressure in the jugular vein and increased intracranial pressure, and an increase in the episcleral venous pressure, to an elevation of IOP. ${ }^{16} 17$ However, the association between arterial blood pressure and IOP is not entirely clear. While a number of studies have found a higher risk for glaucoma in people with high blood

Table 1 Typical tissue healing times

\begin{tabular}{ll}
\hline Tissue type & Healing time \\
\hline Soft tissue injuries & 3 months \\
Shoulder surgery & $3-6$ months \\
Spinal surgery & $3-12$ months \\
Minor nerve repair & $4-5$ months \\
Major nerve repair & $6-12$ months \\
Tendon repair & 3 months \\
\hline
\end{tabular}


pressure, a study in $2002^{18}$ suggested that people with blood pressure that is low relative to their IOP may be at higher risk for glaucoma. The same study found no higher risk for glaucoma in people with hypertension, and, in fact, high blood pressure was associated with a lower risk.

The normal circadian range for IOP is between 13 and $16 \mathrm{~mm}$ $\mathrm{Hg}$, with the higher pressure occurring in the afternoon in both health and disease ${ }^{19}$ Postoperatively (eg, phacoemulsification, cataract, laser surgery) the IOP typically increases on average by $8 \mathrm{~mm} \mathrm{Hg}$ at $2 \mathrm{~h}$ and is then only $5 \mathrm{~mm} \mathrm{Hg}$ above baseline at $24 \mathrm{~h}$ postoperation. ${ }^{19-26}$

IOP changes between recumbent and sitting positions by about only $2-4 \mathrm{~mm} \mathrm{Hg} .{ }^{27}$ In a study of IOP changes during weightlifting ${ }^{20}$ with and without breath-holding, IOP increased by 4 and $2 \mathrm{~mm} \mathrm{Hg}$, respectively. This suggests that the manoeuvres for spirometry (similar to weightlifting with breath-hold) develop pressure changes that are far lower than the pressure for which IOP-lowering drugs are used postsurgery in patients with glaucoma (ie, $>35 \mathrm{~mm} \mathrm{Hg}$ ). Ironically, during strenuous exercise testing the IOP actually falls by $\sim 8 \mathrm{~mm} \mathrm{Hg}$ in healthy subjects, which is attributed to osmotic changes taking place.

It is generally considered that it is the peaks in IOP that can cause damage postoperatively and that with modern laser techniques healing is complete after a few days, with a safety margin of a week before generating straining pressures being prudent. ${ }^{28}$

Cataract surgery can cause glaucoma so it is very important to minimise any activity that increases internal eye pressure. ${ }^{29}$ Postoperative cataract patients are recommended to (1) minimise vigorous exercise, (2) put on shoes while sitting and without lifting up the feet, (3) kneel instead of bending over to pick something up and (4) avoid lifting. Pressure during spirometry is less than maximum expiratory pressures (eg, $70-200 \mathrm{~cm} \mathrm{H}_{2} \mathrm{O}$ ) but a cough can induce $400 \mathrm{~cm} \mathrm{H}_{2} \mathrm{O}$ which implies that the IOP changes in spirometry are probably not harmful.

The complication rate for cataract surgery is low $(1-3 \%)$, and it is considered that many IOP spikes are probably more associated with routine physical stresses (eg, lifting, straining, rubbing the eyes, etc.). ${ }^{30}$ The role of coughing and sneezing has been studied, including the 'photic' sneeze (exposure to bright light initiating sneezing) being induced by anaesthesia used for eye surgery, and the risks of postoperative damage. ${ }^{21} 22$

Typically laser surgery patients leave the surgical site within an hour of surgery, and vision usually remains blurred for a 2-6 week period. For most patients, tissue healing is complete in $50-60 \mathrm{~h},{ }^{31}$ with most of the tissue repair occurring in the first $24 \mathrm{~h} .{ }^{32}$ Laser surgery complication rates are $\sim 3 \%$ less than conventional (mechanical microkeratome) surgery. The recovery time may also be slightly faster with laser surgery.

There are published recommendations for waiting time before commercial diving after eye surgery ${ }^{33}$ (table 2 ) for a variety of eye operations. It is likely that the pressures from positive (during descent) and negative (on ascent) 'squeezes' of the eye during diving are in excess of the stresses of lung function testing (eg, spirometry, mouth pressures, etc.) and perhaps these should be considered as reasonable evidence for waiting before performing lung function tests.

\section{THORACIC SURGERY}

\section{Evidence of perioperative complications}

Uncomplicated healing of muscle and tendon to allow normal postoperative function takes $\sim 3$ weeks in animals ${ }^{13}$ and $4-6$ weeks in humans. ${ }^{11-13}$ In a European study ${ }^{34}$ of thoracic surgery the overall mortality was $3.8 \%$ for a variety of procedures (pneumonectomy, lobectomy, etc.). ${ }^{94}$ Most deaths were
Table 2 Periods of recovery for eye surgery prior to diving

\begin{tabular}{ll}
\hline Anterior segment surgery & 6 months \\
Cataract: non-corneal valve incision & 3 months \\
Radial keratotomy & 3 months \\
Astigmatic keratotomy & 3 months \\
Vitreoretinal surgery & \\
Vitrectomy & 2 months \\
Retinal detachment repair & 2 months \\
Glaucoma filtering surgery & 2 months \\
Cataract: corneal valve incisions & $1-2$ months \\
Lasik & 1 month \\
Oculoplastic surgery & \\
Sutured wound & 2 weeks \\
Enucleation & 2 weeks \\
Strabismus surgery & 2 weeks \\
Photorefractive keratotomy & 2 weeks \\
Conjunctival surgery & 2 weeks \\
Corneal suture removal & 1 week \\
Argon laser trabeculoplasty or & No wait \\
iridectomy & No wait \\
Yag laser capsulotomy & \\
\hline Reproduced from Butler. ${ }^{33}$ &
\end{tabular}

respiratory $(47.3 \%)$, which emphasises the need to assess lung function preoperatively. There is little evidence that lung function testing was to blame for any of these deaths.

\section{Sternal wound complications}

The mechanism by which maximal lung function testing manoeuvres could affect thoracic surgery patients postoperatively centres around sternal wound complications. These fall into three categories: (1) deep subcutaneous infection, (2) sternal infection and (3) mediastinal infection with sternal dehiscence.

Mediastinitis can contribute to the development of lifethreatening illnesses, such as systemic sepsis, respiratory insufficiency and renal failure. Mediastinitis may result in sternal instability and dehiscence, ${ }^{35} 36$ and is usually evident from 6 days to 3 weeks following surgery. Patients at risk for mediastinitis and dehiscence include: those older than 65 years, those with diabetes, older women (osteoporosis), obese patients, those with chronic obstructive pulmonary disease (COPD) and those subjected to prolonged postoperative ventilation. ${ }^{37}$

Sternal wound complications occur in significant numbers of patients. Upwards of $2.3 \%$ of patients may suffer these complications, with an associated mortality rate of $13-52 \%{ }^{3435} 38$ The mortality after initial discharge and up to the first postoperative year is nearly as high as the in-hospital mortality. ${ }^{38}$

Aggressive coughing and deep breathing manoeuvres, which frequently initiate coughing, are important for purging the lungs of fluid and inflating the lungs to prevent atelectasis after thoracic surgery. These manoeuvres are initiated in the hospital and are a mandatory part of postdischarge respiratory treatment. $^{39-41}$ The percussive expansion associated with coughing puts extreme stress on the sternal wound. Ambulating, getting into and out of bed or chairs, bowel movements and other normal activities also place strain on the sternotomy site. While patients experience this stress on their sternal wound as pain and the feeling that they are 'coming apart', the clinical result may in fact be grave: dehiscence and mediastinal infection. Sternal stability is crucial in preventing these severe sternal wound complications. The techniques used by patients to cough post-thoracotomy (bending forward, holding the wound, etc.) 
may be used if a breathing test is required in the immediate postoperative period.

There is evidence that partial upper sternotomy improves pulmonary function and reduces pain in comparison with standard full sternotomy. ${ }^{42}$

\section{Postoperative physiotherapy}

There is increasing use of starting physiotherapy as soon as possible after thoracic surgery, with growing evidence of clinical benefit. ${ }^{10}{ }^{43-47}$ This not only reduces the recovery time but appears to cause little harm to the recovering patient. Extrapolating from this suggests that performing of forced manoeuvres with care is possible probably within weeks of thoracic surgery.

There are a number of studies that have performed spirometry to monitor recovery in a variety of thoracic surgery procedures and they show that measurements are possible at 2, 8 and $24 \mathrm{~h}$ post-thoracotomy. ${ }^{48}$ There were no reports of complications. Other studies have performed spirometry postoperatively at 1 day ${ }^{49}$ or at 2, 3 and 4 days ${ }^{50} 51$ without reported complications.

Another study of two different local anaesthetic regimes for thoracotomy pain relief performed pulmonary function tests on 68 patients who underwent a standard posterolateral thoracotomy. Pulmonary function was measured using bedside spirometry at 24,32 and $72 \mathrm{~h}$ and showed in the postoperative period a mean improvement of $30 \%$ for $\mathrm{FEV}_{1}, 24 \%$ for forced vital capacity (FVC) and 19\% for peak expiratory flow rate (PEFR) compared with placebo. There was no significant difference between pain scores, opiate requirement or pulmonary function between two different anaesthetics. Together these studies suggest that spirometry performed postoperatively after thoracotomy is both tolerated and possible in patients. However, what is unclear is whether the results are limited by the physiology or the pain. Tests in this period should rarely be required. $^{52}$

\section{EAR OPERATIONS AND INFECTIONS}

In patients with a middle ear infection there is a risk that the forced manoeuvres (spirometry or maximal inspiratory pressure (MIP)/maximal inspiratory pressure (MEP)) could cause the ear drum to rupture. At the very least the patient could experience excessive pain, but this is likely to be self-limiting as they refuse to do further testing. If testing is not urgent, then postponing spirometry until the infection has subsided may be beneficial.

\section{BRAIN SURGERY}

There are no clear published guidelines on lung function after brain surgery. Most texts refer to $3-6$ weeks postoperative uncomplicated recovery depending on the degree of surgery. It is likely that forced manoeuvres should be avoided in the first few weeks, but more gentle tests could be performed in the immediate postoperative period. Preoperative assessments for brain tumour surgery may detect underlying lung disease and help anticipate postsurgical complications.

\section{PREGNANCY}

Normal pregnancy is a physiological state and not a medical condition, so lung function should not present any special problems to pregnant women requiring lung function tests. A lax cervix leading to third trimester abortion is treated with a Shirodka suture where 'bearing down' may not a good idea in these patients. There are a variety of studies of lung function in human pregnancy, including spirometry, ${ }^{53}$ lung volumes, ${ }^{53} 54$ airway resistance, ${ }^{55}$ maximum mouth pressures, ${ }^{56}$ gas transfer ${ }^{54} 57-59$ or maximum oxygen uptake ${ }^{60}$ during swimming and cycling in the third trimester. Most find normal values and report no complications in women.

However, the complications of pregnancy such as preeclampsia, risk of early delivery and respiratory disease all present risks to both the mother and fetus/baby and need consideration. Pregnant women with respiratory complications such as cystic fibrosis ${ }^{61}$ asthma ${ }^{62}{ }^{63}$ COPD $^{64}$ and other common lung disease can require full lung function tests. The problem is not in the difficulty or risks of performing the tests but usually in interpreting and reporting the results against normal (non-pregnant) reference ranges.

\section{Gas transfer}

The levels of carbon monoxide (CO) in a non-smoking female who is not pregnant will be minimal, despite the endogenous carboxyhaemoglobin ( $\mathrm{COHb}$ ) levels estimated to be $\sim 0.1-1.0 \%$. If this is translated into exhaled $\mathrm{CO}$, then this is $\sim 6-8 \mathrm{ppm}$. If a subject lives in a town and is exposed to vehicle fumes, this will raise the $\mathrm{COHb}$ to $\sim 1.5-2.0 \%$ or $\sim 10 \mathrm{ppm} .{ }^{65}$ A value of $10 \mathrm{ppm}$ is the normal upper limit set to differentiate smokers from non-smokers-although some workers use values as low as $6 \mathrm{ppm}$. Smokers with expired CO values of 11-21 $\mathrm{ppm}$ are defined as mild smokers, whereas those with expired CO values of $<21 \mathrm{ppm}$ are defined as heavy smokers. ${ }^{66}$ The mean calculated increase in $\mathrm{COHb}$ per gas transfer test is only $0.65 \pm 0.1 \%{ }^{67}$ and is similar whether the subject performs $4-6$ tests. This presents very little significant risk to the mother or unborn child/fetus.

In asthma patients with airway inflammation, values of 10-11 ppm have been found as exhaled CO. Domestic gas cookers are believed to produce levels many times higher than this.

If a subject performing a gas transfer test inhales two attempts at $0.30 \% \mathrm{CO}$ and breath-holds for $10 \mathrm{~s}$ it does increase $\mathrm{COHb}$ but to such a small extent that corrections for back pressure are not necessary. Extrapolating these data to human pregnancy would suggest that the rise in $\mathrm{COHb}$ would be no greater than for someone exposed to normal environmental air pollution and actually well within the normal range of exhaled $\mathrm{CO}$. Since the half-life of $\mathrm{COHb}$ is $\sim 4 \mathrm{~h}$, there is an infinitesimally small increase in risk to the patient and to the developing fetus/baby. This increase would be less than what a pregnant woman would be exposed to under normal daily conditions, assuming she was a non-smoker. If she had moderately well controlled asthma but with some airway inflammation, then the background $\mathrm{COHb}$ would actually swamp any increase in $\mathrm{COHb}$ due to inhaling $\mathrm{CO}$ during the test.

The risks to the developing baby from carbon monoxide in the $\mathrm{CO}$ transfer tests is insignificant compared with the risks from exposure to cigarette smoking during pregnancy.

\section{Postpartum}

Traditionally postpartum bed rest was the standard practice on maternity wards, but more recently this has been questioned and many postpartum activity restrictions are regarded as being needlessly restrictive ${ }^{68}$ Therefore, it appears there is little reason to exclude women who urgently need lung function tests in the postpartum period.

\section{Pre-eclampsia}

Pre-eclampsia by its definition can produce extremely high blood pressure values which on exposure to forced exertions (eg, 
spirometry) could lead to cranial blood vessel rupture or neurophysiological sequelae, and should be avoided where possible. However, for the requirements of the anaesthetist with a patient with pre-eclampsia who has lung disease undergoing emergency surgery a relaxed vital capacity manouvre would at least produce a minimal vital capacity. Usually the risk to mother and baby is so high that emergency surgery (if required) would go ahead anyway.

\section{RESPIRATORY DISORDERS Pulmonary embolus}

For clinical purposes, massive pulmonary embolus (PE) is defined as pulmonary embolism with either haemodynamic collapse or an occlusion of the pulmonary artery that exceeds $50 \%$ of its cross-sectional area. The overall mortality rate associated with massive PE remains at $\sim 30 \%$. ${ }^{69}$

Risk of death is reduced from $30 \%$ to $1-2 \%$ if patients are on anticoagulant treatment after PE. ${ }^{69}$ Therefore, lung function tests should only be performed if required while the patient is on anticoagulant treatment.

\section{Pleural effusion}

Lung function tests can be performed in the presence of a pleural effusion and are often used in diagnosis of the problem with the symptoms of pleuritic pain and dyspnoea. After the effusion has been drained it is possible to perform lung function tests, although this may be limited by pain. One published report described spirometry within 24 h of draining a pleural effusion. ${ }^{70}$ As always the balance between discomfort and meaningful clinical results needs to be considered.

\section{Pneumothorax}

Primary spontaneous pneumothorax rarely happens during strenuous exercise. ${ }^{71}$ Once sealed, the rate of re-absorption of air in the pleural space is $1.24 \%$ of the volume of the pneumothorax in each $24 \mathrm{~h}^{72}$ so recovery can take 16 days for a $20 \%$ pneumothorax. The main risk of pneumothorax is discomfort and pain rather than death. Most patients could therefore safely undertake lung function testing 2 weeks after treatment.

\section{Haemoptysis}

Unexplained haemoptysis is a concern because the exertion of the test may cause further bleeding and run the risk of further morbidity by aspiration into the non-bleeding lobe or lung. Haemoptysis is a serious symptom which could indicate the presence of thoracic vascular injury, arteriovenous malformation, leaking thoracic aneurysm, etc. ${ }^{73}$ It is also worth considering that performing a gas transfer test will produce an erroneous overestimation if there is fresh occult blood in the airway, so it either may not be helpful to perform the test anyway or else it could help in the diagnosis (eg, Goodpasture's syndrome).

\section{CARDIAC AND CARDIOVASCULAR DISORDERS Aneurysms}

The repair of aneurysms has evolved enormously, with internal 'stenting' under radiographic image control replacing surgical intervention. Exercise ECG was undertaken postoperatively on patients at the Mayo clinic who had ascending aortic aneurysm (AAA) repair and they had no problems (ie, rupturing) in 1000 cases. $^{74}$

A large $(>6 \mathrm{~cm})$ or bulging aneurysm would cause concern of a rupture when performing lung function tests, but for standard AAAs it is probably safe. If the AAA has grown quickly then it would be recommended to discuss such cases with a vascular surgeon before proceeding with spirometry. The dilemma is often that the patient will need preoperative spirometry for the surgeons to predict their outcome after surgery. More data need to be collected on what actually happens and how many lung function tests are performed safely with AAAs $>6 \mathrm{~cm}$.

\section{Myocardial infarction (MI)}

One week after an MI most patients are deemed to be stable. However, the definition of 'stable' is not clear. Recent American Thoracic Society (ATS)/European Respiratory Society (ERS) recommendations ${ }^{3}$ suggest waiting for 1 month post-MI before undertaking lung function tests, but there is no evidence base for this.

Exercise testing 1 week after MI appears to be safe. The incidence of fatal cardiac events, including fatal MI and cardiac rupture, is $0.03 \%$, for non-fatal MI and successfully resuscitated cardiac arrest it is $0.09 \%$, and for complex arrhythmias, including ventricular tachycardia, it is $1.4 \%$. Symptom-limited protocols have an event rate that is 1.9 times that of submaximal tests, although the overall fatal event rate is quite low. ${ }^{75-77}$ The majority of the safety data are based on exercise testing performed $>7$ days after MI. The number of patients reported at 4-7 days was more limited, and typically time was reported as a mean value or a range so that it is impossible to determine how many patients were studied at 4 days.

The safety data on exercise testing post-MI show that most patients are stable after 7 days so it is reasonable to perform lung function tests safely after this time.

\section{Vascular surgery}

The time needed following vascular surgery (especially lower limb) before full respiratory exercise tests are performed is typically 4-6 weeks ( $\mathrm{T}$ Fail and G Hamilton personal communication 2010).

\section{Hypertension}

Uncontrolled high blood pressure can cause damage to blood vessels (aneurysm, atherosclerosis), the heart (angina, failure, enlarged heart, etc.) and the brain (transient ischaemic attack, stroke, seizures and encephalopathy).

Given the evidence on treating acute hypertension and the risks of stroke it may be logical to apply the recommendation that mean arterial pressure is maintained at $<130 \mathrm{~mm} \mathrm{Hg}$ during the first $6-12 \mathrm{~h}$ from the start of antihypertensive treatment in order to keep an intracerebral haemorrhage from enlarging. ${ }^{78}$ Antihypertensive treatment should be used which should control blood pressure towards normal values (mean arterial pressure is maintained at $<130 \mathrm{~mm} \mathrm{Hg}$ ) before forced manoeuvres (eg, mouth pressures or spirometry) are attempted. However, patients on new hypertensive drugs may have dizzy spells or syncope from the forced manoeuvres of spirometry. Where suspicion of severe hypertension is high, blood pressure should be measured prior to testing. More evidence is needed to support these recommendations.

\section{Stroke}

Apart from any physical incapability (eg, ability to hold mouthpiece, facial palsy, etc.) brought on by acute stroke, once the patient is stabilised on anticoagulation and/or antihypertensive medication there is little reason why lung function tests cannot be performed. Many patients with COPD have stroke as a co-morbidity and often spirometry may be performed to optimise COPD interventions poststroke. Patients with a facial palsy may require assistance to get a good seal with the spirometer, but there is no published evidence of risks from lung function testing in this patient group poststroke. 


\section{Angina}

Unstable angina is recognised as a serious contraindication for lung function testing. ${ }^{2}{ }^{3}$ However, physical activity bringing on angina as a presymptom of acute MI is a poor prognostic indicator. ${ }^{79}$ The need for spirometry preoperatively in a patient with chronic stable angina (eg, coronary artery bypass graft (CABG) or aortic valve replacement) is a common demand in lung function departments. The use of sublingual GTN (glyceryl trinitrate) prior to testing is often sufficient to avoid symptoms and enable useful lung function tests to be performed.

\section{Arrhythmia}

Apart from extreme exercise, there is little risk from performing lung function tests in patients with an arrhythmia. Patient anxiety and discomfort may affect the results and limit performance, but there are no published guidelines against performing exertional manoeuvres.

\section{Postpacemaker implant}

Generally a few weeks is usually enough for the pacemaker site wound to heal, and there have been no published precautions in this area.

\section{INFECTIVE CONTRAINDICATIONS}

Contraindications for lung function tests in relation to infections can fall into several categories:

1. Harm to the patient from performing the test.

2. Pain or discomfort for the patients (eg, vomiting, diarrhoea, cold sores, common cold).

3. Harm to staff or other patients (contagious disease, infections).

4. Redundant results because of submaximal effort from patients that are feeling unwell.

5. The results do not contribute to the clinical plan.

The main infectious diseases that would present a risk of cross-infection in the lung function department or other lung function testing facility include TB and hepatitis B.

General infection control procedures should be adopted in accordance with international guidelines to stop the spread of nosocomial infections (eg, influenza, pneumonia, methicillinresistant Staphylococcus aureus (MRSA) and Clostridium difficile). These have been covered elsewhere in a review of best practice. ${ }^{80}$

\section{CONTRAINDICATIONS IN SPECIFIC TESTS IN RESPIRATORY PHYSIOLOGICAL MEASUREMENT}

There are several relative contraindications for specific tests carried out by practitioners of lung function. The key tests covered are described.

\section{Contraindications for arterial blood gas sampling}

Factors significantly increasing the risk of arterial puncture include the existence of aortic valvular incompetence in the patient, systemic anticoagulation at the time of the arterial puncture and the presence of arteriosclerosis or hypertension in the patient. ${ }^{81}$

\section{Contraindications for lung volume estimation}

With respect to whole-body plethysmography, relative contraindications include factors such as claustrophobia, upper body paralysis, obtrusive body casts, intravenous pumps or other conditions that immobilise or prevent the patient from fitting into or gaining access to the 'body box'. In addition, the procedure may necessitate stopping intravenous treatment or supplemental oxygen. There are similar risks with other lung volume estimations (gas dilution/nitrogen washout) during the maximum inspiration to total lung capacity or expiration to residual volume manoeuvres. There is a theoretical risk of exposure to high oxygen levels during nitrogen washout test in patients who have $\mathrm{CO}_{2}$ retention-but the short duration of the measurement will render this harmless.

\section{Contraindications for bronchodilator testing}

The number of contraindications to administering short-acting $\beta_{2}$-sympathomimetics by inhalation is limited. ${ }^{82}{ }^{83}$ Prudence is called for in patients with:

- Thyrotoxicosis;

- Heart failure;

- Hypertension;

- Tachydysrhythmias (can be provoked by $\beta_{2}$-agonists);

- Decreased glucose tolerance;

- Unstable diabetes mellitus; and

- Concomitant use of cardiac glycosides.

However, the risk of a single administration, for diagnostic purposes, is minimal.

Apart from 'hypersensitivity' to atropine-like substances, anticholinergics administered by inhalation have few known contraindications.

\section{Contraindications for other lung function-related services}

Since the original AARC contraindications were published, many lung function departments and units offer physiological measurements services not originally considered for having contraindications. These include:

- Sleep studies, including overnight oximetry;

- Skin testing;

- Continuous positive airways pressure (CPAP) and noninvasive ventilation (NIV) adaptation;

- Bronchial challenge testing;

- Compliance measurement;

- Oxygen assessments;

- Blood gas measurements;

- Bronchodilator response (ultrasonic nebuliser-induced bronchospasm); and

- Oscillometry.

Contraindications for these procedures are summarised here. Again, many of the recommendations are based on expert opinion.

\section{Sleep studies, including overnight oximetry}

Patients who could be at risk from strangulation from wires and leads used in monitoring devices need a risk assessment to be performed. Children are at particular risk. Somnambulists could pull equipment on top of themselves, although the more recent use of 'Holter' type measuring devices decreases this risk.

\section{Skin testing}

Relative contraindications should be applied to patients with known anaphylactic responses, persistent severe or unstable asthma, pregnancy and those with a known severe initial allergic reaction. Systemic collapse and fatalities have been reported, and these are more common in infants and in patients where the reaction was systemic (food allergy, latex, insect stings).

Ensure no antihistamines, tricyclic antidepressants, some antinauseants and topical (not oral) steroids are used because they can alter the results of the test. $\beta$-Blockers and angiotensinconverting enzyme (ACE) inhibitors should be used with caution. Guidelines for skin prick testing are available. ${ }^{84}$ 


\section{Home CPAP and NIV issues}

CPAP should be avoided in patients with middle ear infections or severe sinusitis. Other complications can include sores over the bridge of the nose, dryness of the nose and leaks from the edges of the mask causing dry eyes. However, having no leak suggests that the mask may be too tight, leading to the development of facial sores. Any patient with a pneumothorax should be referred for specialist ventilation in the intensive care unit (ICU)/high dependency unit (HDU) setting.

\section{Bronchial challenge}

Extreme caution should be taken with patients who have 'brittle asthma' or who have shown strong anaphylactic response in the past. Nebulised bronchodliators should be immediately available, together with an emergency resuscitation trolley. Guidelines have been published ${ }^{85}$ which show the absolute and relative contraindications:

\section{Absolute contraindications}

- Severe acute airflow limitation: $\mathrm{FEV}_{1}<50 \%$ of predicted.

- Heart attack or stroke in last 3 months.

- Uncontrolled hypertension: systolic blood pressure $>200 \mathrm{~mm}$ $\mathrm{Hg}$ or diastolic pressure $>120 \mathrm{mmHg}$.

- Known history of aortic aneurysm.

\section{Relative contraindications}

- Moderate airflow limitation: $\mathrm{FEV}_{1}<60 \%$ of predicted or $<1.5$ litres.

- Inability to perform spirometry of acceptable quality.

- Pregnancy.

- Nursing mothers.

- Current use of cholinesterase inhibitor medication (for myasthenia gravis).

Occasionally, it is not possible to perform valid lung function tests on patients who have contraindications or are confused/ very unwell. Well trained staff will either postpone the test or comment on the limitations. The results may be uninterpretable. Three large lung function centres in the UK report a $0.3-0.5 \%$ cancellation rate due to contraindications per year.

\section{Blood gas measurements}

Patients with clotting problems (heparin, thrombocytopenia with a platelet count of $<100 \times 10^{9} / 1$ or patients on anticoagulants) should not have arterial stabs but should be offered an ear lobe capillary blood gas measurement. Patients with haemophilia or a platelet count of $>100 \times 10^{9} / 1$ are generally at low risk from an arterial stab, but those with a count of $50-100 \times 10^{9} / 1$ are at increased risk of bleeding. In hypoxaemic patients capillary blood gases correctly performed are just as reliable as arterial stabs. ${ }^{81} 86-89$

\section{Oxygen assessments}

Oxygen assessments have the risks from carbon dioxide retention leading to narcosis, plus the risk of arterial gas measurements indicated above. Assessing patients according to evaluated criteria should include screening with oximetry before a blood gas measurement is made.

\section{Lung compliance measurement}

The safety of pressure-volume curves has been evaluated and shown to be acceptable in most patients in a critical care setting. In acutely ill patients they can lead to hypoxaemia and haemodynamic changes which require close monitoring. ${ }^{90}$

\section{PAEDIATRICS}

Lung function testing on children will present similar contraindications to testing adults, but in general more care needs to be taken in terms of observation and monitoring during testing. It is recommended that a pulse oximeter is used when testing in infants. ${ }^{91}$ The added complications of sedation in infants have also been covered elsewhere, but such studies are usually limited to highly specialised centres with trained and experienced personnel. ${ }^{91}$

\section{RESEARCH RECOMMENDATIONS}

Clearly from this review, it is apparent that the evidence base is lacking in many areas as regards contraindications for lung function testing. It would be prudent if over the course of the next few years departments and practitioners considered either prospective or retrospective investigations or audit into the following areas of uncertainty.

Review or audit of patients undergoing preoperative lung function assessments and how many of them have complications either during or just after testing should be carried out in the following groups of patients:

Aneurysms

Eye surgery

Laparotomy

Table 3 Summary of contraindications and the main reason to avoid testing

\begin{tabular}{lll}
\hline Contraindication & Reason to avoid lung function testing* & Recommendation \\
\hline Thoracic/abdominal surgery & Rupture site of injury, avoid pain, discomfort & Relative \\
Brain, eye, ear, ENT surgery & Rupture site of injury, avoid pain, discomfort & Relative \\
Pneumothorax & Worsen pneumothorax, avoid discomfort and pain & Relative \\
Myocardial infarction & Induce further infarction leading to cardiac arrest & Absolute/relative \\
Ascending aortic aneurysm & Rupture of aneurysm, catastrophic/fatal event & Absolute/relative \\
Haemoptysis & Pulmonary emboli or myocardial infarction & Relative \\
Pulmonary embolism & Death, hypoxia leading to respiratory failure & Absolute/relative \\
Acute diarrhoea & Discomfort, embarrassment, infection risk & Relative \\
Angina & May lead to cardiac arrest in severe cases. discomfort & Absolute/relative \\
Severe hypertension (systolic $>200 \mathrm{~mm} \mathrm{Hg}$, diastolic & Risk of blackout/collapse, rupture of cerebral blood & Measure blood pressure before tests if suspected \\
$>120$ mm Hg) & vessels, etc. & \\
Confused/demented patients & Lung function tests are volitional and need patient & Balance need for test against difficult in obtaining results \\
Patient discomfort & cooperation & Wait until main symptoms abate \\
Infection control issue & Vomiting, diarrhoea, cold sores, common cold & Wait until main symptoms abate \\
\hline
\end{tabular}

${ }^{*}$ Sometimes the risk may be necessary as a preoperative assessment for life-saving surgery.

Recommendation: absolute, lung function testing should be avoided in most cases; relative, judge each case on its merits 
Inguinal hernia

Pleural effusion

Pneumothorax

Post-MI.

Other useful areas of research would include

Changes in intraocular pressure during spirometry

Changes in blood pressure during spirometry

Reviews of complications after surgical procedures where lung function testing is performed in the perioperative period

Review of lung function testing-related complications with keyhole surgery

Review of lung function testing during pregnancy.

\section{CONCLUSIONS}

There are some limited or absolute contraindications for performing lung function tests (unstable cardiovascular conditions, etc.) but most are relative contraindications. These have been summarised in table 3 and appendix 2 .

The risks of any test must be outweighed by the benefit gained.

While modern surgical techniques have decreased the amount of tissue intervention and reduced healing times, there is still a case for allowing large muscle masses to heal for 4-6 weeks before testing of lung function is resumed. The risks to eye surgery and patients receiving less invasive surgery is much less, and healing times suggest that waiting for $2-3$ weeks may be sufficient.

There needs to be more research and audit to investigate whether lung function tests do actually present any risks and also what evidence there is for a minimum time before tests are measured postsurgery or cardiovascular event.

Acknowledgements I am grateful to a number of colleagues who have provided expert advice and opinion on various areas. These include Drs Mick Davies and Sara Thorne, Consultant Cardiological Physicians, UHB, Dr Rosalind Harrison, Consultant Ophthalmic Surgeon, Burton on Trent, Dr Martin Miller, Consultant Respiratory Physician University Hospital Birmingham, Dr Dan Veale, University Hospital, Grenoble, France. I am also grateful to colleagues who have provided information on the ARTP Forum, but especially Dr Adrian Kendrick, Bristol Royal Infirmary, Mr Trefor Watts, Walsall Manor Hospital and Mr Derek Cramer Royal Brompton Hospital.

Competing interests None.

Provenance and peer review Not commissioned; not externally peer reviewed.

\section{REFERENCES}

1. Anon. Contraindications to use of spirometry. AARC clinical practice guidelines spirometry. 1996 Update. Respir Care 1996:41:629-36.

2. Anon. BTS/ARTP guidelines for the measurement of respiratory function. Respir Med 1994;88:165-94.

3. Miller MR, Crapo R, Hankinson J, et al. ATS/ERS standardisation of lung function testing: general considerations for lung function testing. Eur Respir $J$ 2005:26:153-61.

4. Miller WF, Scacci R, Gast LR. Laboratory evaluation of pulmonary function. Philadelphia: JB Lippincott Co, 1987.

5. Montenegro HD, Chester EH, Jones PK. Cardiac arrhythmias during routine tests of pulmonary function in patients with chronic obstruction of airways. Chest 1978;73:133-9

6. Macguire B, Royse C, Royse A, et al. Lung function following cardiac surgery is not affected by postoperative ventilation time. Ann Thorac Cardiovasc Surg 2000;1:13-18.

7. Nicholson DJ, Kowalski SE, Hamilton GA, et al. Postoperative pulmonary function in coronary artery bypass graft surgery patients undergoing early tracheal extubation: a comparison between short-term mechanical ventilation and early extubation. $J$ Cardiothoracic Vac Anaesth 2002;10:27-31.

8. Weissman C. Pulmonary function after cardiac and thoracic surgery. Anesth Analg 1999:88:1272-9.

9. Ooi A, Goodwin A, Goddard M, et al. Clinical outcome versus post-mortem finding in thoracic surgery: a 10-year experience Eur J Cardiothorac Surg 2003;23:878-82.

10. Westerdahl E, Lindmark B, Eriksson $T$, et al. Deep-breathing exercises reduce atelectasis and improve pulmonary function after coronary artery bypass surgery. Chest 2005;128:3482-8
11. Cross KJ, Mustoe TA. Growth factors in wound healing. Surg Clin North Am 2003;83:531-45

12. Witte MB, Barbul A. General principles of wound healing. Surg Clin North Am 1997:77:509-28

13. Montgomery RD. Healing of muscle, ligaments, and tendons. Semin Vet Med Surg (Small Anim) 1989:4:304-11.

14. McCormack K, Scott NW, Go PM, et al. Laparoscopic techniques versus open techniques for inguinal hernia repair. Cochrane Database Syst Rev 2005;(1):CD001785

15. Nguyen NT, Lee SL, Goldman C, et al. Comparison of pulmonary function and postoperative pain after laparoscopic versus open gastric bypass: a randomized trial. J Am Coll Surg 2001;192:469-76.

16. Leung D, Lam D. The relationship of intraocular pressure to intracranial pressure. Ann Emerg Med 2005;45:98-9.

17. Jonas JB. Tight necktie, intraocular pressure, and intracranial pressure. $\mathrm{Br} \mathrm{J}$ Ophthalmol 2005:89:786-7.

18. Heijl A, Leske MC, Bengtsson B, et al. Reduction of intraocular pressure and glaucoma progression: results from the Early Manifest Glaucoma Trial. Arch Ophthalmol 2002;120:1268-79.

19. Perlman JI, Delany CM, Sothern RB, et al. Intraocular pressure. Physiology Clin Ter 2007:158:31-47.

20. Vieira GM, Oliveira HB, de Andrade TD, et al. Intraocular pressure variation during weight lifting. Arch Ophthalmol 2006;124:1251-4.

21. Wessels IF, Wessels DA, Zimmerman GJ. The photic sneeze reflex and ocular anesthesia. Ophthalmic Surg Lasers 1999;30:208-11.

22. Semes LP, Amos JF, Waterbor JW. The photic sneeze response: a descriptive report of a clinic population. J Am Optom Assoc 1995;66:372-7.

23. Byrd S, Singh K. Medical control of intraocular pressure after cataract surgery. J Cataract Refract Surg 1998:24:1493-7.

24. Thirumalai B, Baranyovits PR. Intraocular pressure changes and the implications on patient review after phacoemulsification. J Cataract Refract Surg 2003;29:504-7.

25. Whitefield L, Crowston J, Little BC. First day follow up for routine phacoemulsification? Br J Ophthalmol 1996;80:148-50.

26. Ahmed II, Kranemann C, Chipman M, et al. Revisiting early postoperative follow-up after phacoemulsification. J Cataract Refract Surg 2002;28:100-8.

27. Shapiro A, Wolf E, Ferber I, et al. The effect of physical activity on the intraocula pressure of glaucomatous patients. Eur J Appl Physiol 1983;52:136-8.

28. Royal College of Ophthalmologists. Guidelines for Cataract Surgery. London: Royal College of Ophthalmologists, 1995.

29. Desai P. The National Cataract Surgery Survey: II. Clinical outcomes. Eye 1993; 7:489-94.

30. Pearson PA, Owen DG, Van Meter WS, et al. Vitreous loss rates in extracapsular cataract surgery by residents. Ophthalmology 1989:96:1225-9.

31. Yülek F, Ozdek S, Gürelik G, et al. Effect of topical steroids on corneal epithelial healing after vitreoretinal surgery. Acta Ophthalmol Scand 2006;84:319-22.

32. Hardarson $\mathbf{T}$, Hanson $\mathrm{C}$, Claesson $\mathrm{M}$, et al. Time-lapse recordings of human cornea epithelial healing. Acta Ophthalmol Scand 2004;82:184-8.

33. Butler FK. Diving and hyperbaric ophthalmology, Surv Ophthalmol 1995;39: 347-66.

34. Ooi AT, Goodwin AT, Goddard M, et al. Clinical outcome versus post-mortem finding in thoracic surgery: a 10-year experience. Eur J Cardiovasc Surg 2003:23:878-81.

35. Norris So. Managing postoperative mediastinitis. J Cardiovasc Nurs 1989;3:52-65

36. Sarr MG, Gott VL, Townsend TR. Mediastinal infection after cardiac surgery. Ann Thorac Surg 1984;38:415-23.

37. Ottino G, Depaulis R, Pansini S, et al. Major sternal wound infection after open-hear surgery: a multivariate analysis of risk factors in 2,579 consecutive operative procedures. Ann Thorac Surg 1987:44:173-9.

38. Hamilton W, McDonald J, Fisher $\mathrm{H}$, et al. Postoperative respiratory complications Anaesthesiology 1964;25:607-12.

39. Bartlett R, Gazzaniga A, Geraghty T. Respiratory maneuvers to prevent postoperative pulmonary complications: a critical review. J Am Med Assoc 1973;224:1017-21.

40. Kempainen RR, Benditt JO. Evaluation and management of patients with pulmonary disease before thoracic and cardiovascular surgery. Semin Thorac Cardiovasc Surg 2001;13:105-15.

41. Trayner E, Bartolome RC. Postoperative pulmonary complications. Med Clin North Am 2001;85:1129-39.

42. Candaele S, Herijgers $P$, Demeyere $R$, et al. Chest pain after partial upper versus complete sternotomy for aortic valve surgery. Acta Cardiol 2003:58:17-21.

43. Johnson D, Kelm C, Thomson D, et al. The effect of physical therapy on respiratory complications following cardiac valve surgery. Chest 1996:109:638-44.

44. Lawrence VA, Page CP, Harris GD. Perioperative spirometry before and after abdominal operations: a critical appraisal of its predictive value. Intern Med 1989:149:280-5

45. Oikkonen $\mathbf{M}$, Karjalainen $\mathrm{K}$, Kahara $\mathrm{V}$, et al. Comparison of incentive spirometry and intermittent positive pressure breathing after coronary artery bypass graft. Chest 1991;99:60-5

46. Carragee EJ, Helms E, O'Sullivan GS. Are postoperative activity restrictions necessary after posterior lumbar discectomy? A prospective study of outcomes in 50 consecutive cases. Spine 1996;21:1893-7.

47. Weissman C. Pulmonary function after cardiac and thoracic surgery. Anesth Analg 1999:88:1272-7.

48. Shulman M, Sandler AN, Bradley JW, et al. Post-thoracotomy pain and pulmonary function following epidural and systemic morphine. Anesthesiology 1984:61:569-75. 
49. Landreneau RJ, Pigula F, Luketich JD, et al. Acute and chronic morbidity differences between muscle-sparing and standard lateral thoracotomy. J Thorac Cardiovasc Surg 1996;112:1346-51.

50. Cimen S, Ozkul V, Ketenci B, et al. Daily comparison of respiratory functions between on-pump and off-pump patients undergoing CABG. Eur J Cardiothorac Surg 2003:23:589-94

51. Westerdahl E, Lindmark B, Almgren SO, et al. Chest physiotherapy after coronary artery bypass graft surgery: a comparison of three different deep breathing techniques. J Rehabil Med 2001:33:79-84.

52. Barron DJ, Tolan MJ, Lea RE. A randomized controlled trial of continuous extrapleural analgesia post-thoracotomy: efficacy and choice of local anaesthetic. J Vasc Surg 1986;3:389-404.

53. Norregaard 0, Schultz $\mathrm{P}$, Ostergaard A, et al. Lung function and postural change during pregnancy. Respir Med 1989;83:467-70.

54. Gaziouglu K, Kaltieder NL, Rosen $\mathrm{M}$, et al. Pulmonary function during pregnany in normal women and in patient with cardiopulmonary disease. Thorax 1970;25 445-50.

55. Gee JBL, Parker BS, Millen JE, et al. Pulmonary mechanics during pregnancy. J Clin Invest 1967; 46:945-52

56. Gilroy RJ, Mangura BT, Lavietes MH. Rib-cage and abdominal volume displacements during breathing in human pregnancy. Am Rev Respir Dis 1988; 137:668-72.

57. Krumholz RA, Echt CR, Ross JC. Pulmonary diffusing capacity, capillary blood volume, lung volumes and mechanics of ventilation in early and late pregnancy. $J$ Lab Clin Med 1964;63:648-55.

58. McAuliffe F, Kametas N, Rafferty GF, et al. Pulmonary diffusing capacity in pregnancy at sea level and at high altitude. Respir Physiolo Neurobiol 2003:134:85-92.

59. Milne JA, Mills RJ, Coutts JR, et al. The effect of human pregnancy on the pulmonary transfer factor for carbon monoxide as measured by the single breath method. Clin Sci Mol Med 1977:53:271-6.

60. Spinnewijn WEM, Wallneburg HCS, Struijk PC, et al. Peak ventilatory responses during cycling and swimming in pregnant and non-pregnant women. J App Physiol 1996:81:738-42.

61. Edenborough FP, Stableforth DE, Webb AK, et al. Outcome of pregnancy in women with cystic fibrosis. Thorax 1995:50:170-4.

62. Clark SL. Asthma in pregnancy. Obstet Gynaecol 1993;82:1036-40.

63. Stenius-Aarniala B, Riikonen S, Teramo K. Slow release theophylline in pregnant asthmatics. Chest 1995;107:642-7.

64. Hornby PJ, Abrahams TP. Pulmonary pharmacology. Clin Obstet Gynecol 1996;39:17-35.

65. De Bruin YB, Carrer $\mathrm{P}$, Jantunen $\mathrm{M}$, et al. Personal carbon monoxide exposure levels: contribution of local sources to exposures and microenvironment concentrations in Milan. J Expo Anal Environ Epidemiol 2004;14:312-22.

66. Groman E, Blauensteiner D, Kunze U, et al. Carbon monoxide in the expired air of smokers who smoke so-called "light" brands of cigarettes. Tob Control 2000:9:352.

67. Normand H, Lavigne F, Mouadil A. Performing the apnea of the single-breath carbon monoxide diffusing capacity: relaxation on the shutter or full inspiration with near atmospheric intrapulmonary pressure? Chest 2006;130:207-13.

68. Weir LF, Nygaard IE, Jason Wilken J, et al. Postoperative activity restrictions. any evidence? Obstet Gynecol 2006;107:305-9.

69. Konstantinov IE, Saxena P, Koniuszko MD, et al. Acute massive pulmonary embolism with cardiopulmonary resuscitation: management and results. Tex Heart Inst J 2007;34:41-6.

70. Light RW, Stansbury DW, Brown SE. The relationship between pleural pressures and changes in pulmonary function after therapeutic thoracentesis. Am Rev Respir Dis 1986; 133:658-61.

71. Bense L, Wiman LG, Hedenstierna G. Onset of symptoms in spontaneous pneumothorax: correlations to physical activity. Eur Respir Dis 1987;71:181-6.

72. Kircher LT, Swartzel RL. Spontaneous pneumothoraxand its treatment. JAMA 1954;155:24

73. Eddy JB. Clinical assessment and management of massive hemoptysis. Crit Care Med 2000;28:1642-7.

74. Hertzer N, Beven E, Young J, et al. Coronary artery disease in peripheral vascular patients: a classification of 1000 coronary angiograms and results of surgical management. Ann Surg 1984;199:223-33.

75. Hamm LF, Crow RS, Stull GA, et al. Safety and characteristics of exercise testing early after acute myocardial infarction. Am J Cardiol 1989;63:1193-7.

76. Nielsen JR, Mickley H, Damsgaard EM, et al. Predischarge maximal exercise test identifies risk for cardiac death in patients with acute myocardial infarction. $\mathrm{Am} \mathrm{J}$ Cardiol 1990:65:149-53.

77. Senaratne MP, Hsu LA, Rossall RE, et al. Exercise testing after myocardial infarction: relative values of the low level pre-discharge and the post-discharge exercise test. J Am Coll Cardiol 1988;12:1416-22.

78. Broderick JP, Adams HP Jr, Barsan W, et al. Guidelines for the management of spontaneous intracerebral hemorrhage: a statement for healthcare professionals from a special writing group of the Stroke Council, American Heart Association. Stroke 1999;30:905-15.

79. Matsuda M, Matsuda $\mathrm{Y}$, Ogawa $\mathrm{H}$, et al. Angina pectoris before and during acute myocardial infarction: relation to degree of physical activity. Am J Cardiol 1985;55:1255-8.
80. Kendrick AH, Johns DP, Leeming JP. Infection control of lung function equipment a practical approach. Respir Med 2003;97:1163-79.

81. Mortensen JD. Clinical sequelae from arterial needle puncture, cannulation, and incision. Circulation 1967;35:1118-23.

82. Kallergis EM, Manios EG, Kanoupakis EM, et al. Acute electrophysiologic effects of inhaled salbutamol in humans. Chest 2005:127:2057-63.

83. Insulander $\mathbf{P}$, Juhlin-Dannfelt $A$, Freyschuss $U$, et al. Electrophysiologic effects of salbutamol, a $\beta_{2}$-selective agonist. J Cardiovasc Electrophysiol 2003;15:316-22.

84. Anon. Skin tests used in type 1 allergy testing. Position paper. Sub-Committee on skin tests of the European Academy of Allergology and Clinical Immunology. Allergy 1989;10(44 Suppl):1-59.

85. Crapo RO, Casaburi $\mathrm{R}$, Coates $\mathrm{AL}$, et al. Guidelines for methacholine and exercise challenge testing - 1999. Am J Respir Crit Care Med 2000;161:309-29.

86. Dar K, Williams $\mathrm{T}$, Aitken $\mathrm{R}$, et al. Arterial versus capillary sampling for analysing blood gas pressures. BMJ 1995:310:24-5.

87. Spiro SG, Dowdeswell IR. Arterialised ear lobe samples for blood gas tensions. $\mathrm{Br} J$ Dis Chest 1976;70:263.

88. Pitkin AD, Roberts CM, Wedzicha JA. Arterialised earlobe blood gas analysis: an underused technique. Thorax 1994;49:364-6.

89. Sauty A, Uldry C, Debétaz LF, et al. Differences in P02 and PCO2 between arteria and arterialized earlobe samples. Eur Respir J 1996;9:186-9.

90. Lee WL, Stewart TE, MacDonald R, et al. Safety of pressure-volume curve measurement in acute lung injury and ARDS using a syringe technique. Chest 2002;121:1595-601.

91. Stocks J, Sly P, Tepper RS, et al. Infant respiratory function testing. New York: Wiley-Liss, 1996.

\section{APPENDIX 1: GUIDE TO RISKS FROM PERFORMING LUNG FUNCTION TESTS}

\begin{tabular}{|c|c|c|c|c|}
\hline Contraindication & Complication & $\begin{array}{l}\text { Likelihood } \\
\text { (A) }\end{array}$ & $\begin{array}{l}\text { Consequence } \\
\text { (B) }\end{array}$ & $\begin{array}{l}\text { Risk } \\
(A \times B)\end{array}$ \\
\hline MI (recent) & Death & 5 & 5 & 25 \\
\hline MI (recent) & Further MI & 5 & 5 & 25 \\
\hline PE (untreated) & Death & 4 & 5 & 20 \\
\hline $\begin{array}{l}\text { Ascending aortic } \\
\text { aneurysm }(>6 \mathrm{~cm})\end{array}$ & Death & 4 & 5 & 20 \\
\hline $\begin{array}{l}\text { Ascending aortic } \\
\text { aneurysm }(>6 \mathrm{~cm})\end{array}$ & MI & 4 & 4 & 16 \\
\hline Pneumothorax & Lung collapse & 3 & 4 & 12 \\
\hline Thoracic surgery & $\begin{array}{l}\text { Further } \\
\text { surgery }\end{array}$ & 3 & 4 & 12 \\
\hline Pneumothorax & Pain & 5 & 2 & 10 \\
\hline $\begin{array}{l}\text { Ascending aortic } \\
\text { aneurysm }(<6 \mathrm{~cm})\end{array}$ & Death & 2 & 5 & 10 \\
\hline Thoracic surgery & Death & 2 & 5 & 10 \\
\hline Haemoptysis & Bleed & 2 & 4 & 8 \\
\hline Angina & MI & 2 & 4 & 8 \\
\hline $\begin{array}{l}\text { Ascending aortic } \\
\text { aneurysm }(<6 \mathrm{~cm})\end{array}$ & $\mathrm{MI}$ & 2 & 4 & 8 \\
\hline Eye surgery (<1 week) & Undo surgery & 2 & 3 & 6 \\
\hline Eye surgery ( $<1$ week) & Undo surgery & 2 & 3 & 6 \\
\hline Abdominal surgery & Pain & 3 & 2 & 6 \\
\hline Thoracic surgery & Pain & 3 & 2 & 6 \\
\hline Haemoptysis & Death & 1 & 5 & 5 \\
\hline Pneumothorax & Discomfort & 5 & 1 & 5 \\
\hline MI (>1 week) & Death & 1 & 5 & 5 \\
\hline PE (treated) & Death & 1 & 5 & 5 \\
\hline Haemoptysis & PE & 1 & 4 & 4 \\
\hline Acute diarrhoea & Discomfort & 4 & 1 & 4 \\
\hline Abdominal surgery & Rupture & 1 & 4 & 4 \\
\hline Angina & Pain & 2 & 2 & 4 \\
\hline PE (treated) & Hypoxia & 1 & 3 & 3 \\
\hline Eye surgery ( $<4$ week) & Undo surgery & 1 & 3 & 3 \\
\hline Eye surgery ( $<4$ week) & Pain & 1 & 2 & 2 \\
\hline $\mathrm{MI}$ (>1 week) & Pain & 1 & 2 & 2 \\
\hline
\end{tabular}

Risk: 1-4, low; 5-9, moderate; 10-19, high; 20-25, very high.

Likelihood: 1, <1\%; 2, 2-10\%; 3, 11-20\%; 4, 21-50\%; 5, >50\%.

Consequence: 1 , discomfort; 2, pain; 3, syncope/bleeding; 4, tissue damage, minor surgery; 5 , emergency care, major surgery, death.

$\mathrm{MI}$, myocardial infarction; $\mathrm{PE}$, pulmonary embolus. 


\section{APPENDIX 2: SUMMARY OF WAIT TIME BEFORE LUNG FUNCTION TESTING}

\begin{tabular}{llll}
\hline Contraindication* & Severity & RR & $\begin{array}{l}\text { Routine wait } \\
\text { weeks }\end{array}$ \\
\hline MI (recent) & Death & 25 & 1 \\
MI (recent) & Further MI & 25 & 1 \\
PE (untreated) & Death & 20 & 1 \\
Ascending aortic aneurysm $(>6 \mathrm{~cm})$ & Death & 20 & 1 \\
Ascending aortic aneurysm $(>6 \mathrm{~cm})$ & MI & 16 & 1 \\
Pneumothorax & Lung collapse & 12 & 3 \\
Thoracic surgery & Further surgery & 12 & 4 \\
Pneumothorax & Pain & 10 & 2 \\
Ascending aortic aneurysm $(<6 \mathrm{~cm})$ & Death & 10 & 1 \\
Thoracic surgery & Death & 10 & 4 \\
Haemoptysis & Bleed & 8 & 0 \\
Angina & MI & 8 & 0 \\
Ascending aortic aneurysm $(<6 \mathrm{~cm})$ & MI & 8 & 1 \\
Eye surgery $(<1$ week) & Undo surgery & 6 & 1 \\
Eye surgery $(>1$ week) & Undo surgery & 6 & 1 \\
\hline
\end{tabular}

Continued

\begin{tabular}{llcl}
\hline Contraindication* & Severity & RR & $\begin{array}{l}\text { Routine wait } \\
\text { weeks }\end{array}$ \\
\hline Abdominal surgery & Pain & 6 & 4 \\
Thoracic surgery & Pain & 6 & 4 \\
Haemoptysis & Death & 5 & 1 \\
Pneumothorax & Discomfort & 5 & 2 \\
MI ( $>1$ week) & Death & 5 & 0 \\
PE (treated) & Death & 5 & 0 \\
Haemoptysis & PE & 4 & 0 \\
Acute diarrhoea & Discomfort & 4 & 0 \\
Abdominal surgery & Rupture & 4 & 4 \\
Angina & Pain & 4 & 0 \\
PE (treated) & Hypoxia & 3 & 0 \\
Eye surgery ( $<4$ week) & Undo surgery & 3 & 1 \\
Eye surgery ( $>4$ week) & Undo surgery & 3 & 1 \\
Ml ( $>1$ week) & Pain & 2 & 1 \\
\hline
\end{tabular}

*Contraindications are relative and sometimes the need to perform the test will override the risks to the patient from the procedure. At these times it is important to get written instructions from a consultant physician, surgeon or anaesthetist to proceed with the tests.

$\mathrm{Ml}$, myocardial infarction; PE, pulmonary embolus.

Advancing Postgraduates. Enhancing Healthcare.

The Postgraduate Medical Journal is dedicated to advancing the understanding of postgraduate medical education and training.

- Acquire the necessary skills to deliver the highest possible standards of patient care

- Develop suitable training programmes for your trainees

- Maintain high standards after training ends

Published on behalf of the fellowship for Postgraduate Medicine

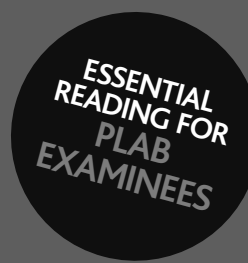

FOR MORE DETAILS OR TO SUBSCRIBE, VISIT THE WEBSITE TODAY

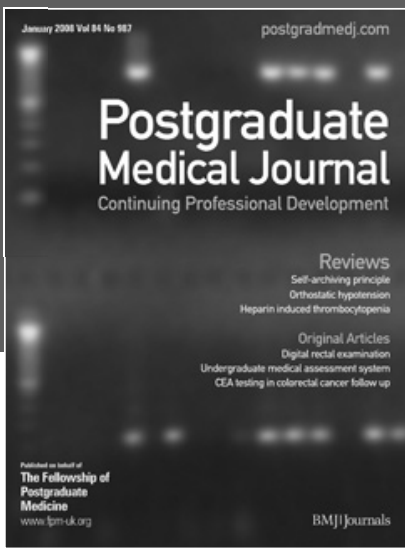

postgradmedj.com

BMJIJournals 